\title{
The Hajj: Hazards of Heat Exposure and Prevalence of Heat Illnesses among Pilgrims
}

\author{
Suhaila Qari
}

\begin{abstract}
Hajj, annually hosted by Saudi Arabia, is considered a religious major mass gathering event that pose significant public health challenges like the transmission of infectious diseases and illnesses related to climate change. Heat stress is a key problem that faced by about two and half millions pilgrims during Hajj. It has historically experienced high morbidity and mortality due to heat illnesses. The highest incidence of mortalities attributed to heat illnesses happened in $1409 \mathrm{Hijri}$ and $1412 \mathrm{Hijri} \mathrm{Hajj}$ as the recorded maximum temperatures reached $48.7^{\circ} \mathrm{C}$ and $47.6^{\circ} \mathrm{C}$ respectively. Holy Makkah area had the highest recoded incidence of these mortalities, since pilgrims stay much longer periods in Makkah compared to Arafat and Mina. This work aimed to review the prevalence of heat illness in general and heat stroke in specific among the pilgrimage during Hajj and summarize the reasons that make pilgrimage more liable to develop heat stroke. This review also describes, in brief, the process of acclimatization to heat stress and the impact of heat stress on the body besides summarizing the common clinical presentation of heat stroke.
\end{abstract}

KEYWORDS: Hajj Saudi Arabia pilgrims, Heat exhaustion, Heat stroke, Heat illnesses, Acclimatization, Heat shock proteins.

This article may be cited as: Qari S. The Hajj: Hazards of Heat Exposure and Prevalence of Heat Illnesses among Pilgrims. J Liaquat Uni Med Health Sci. 2019;18(04):252-7. doi: 10.22442/jlumhs.191840637

\section{INTRODUCTION}

Hajj is the fifth pillar of Islam as it is compulsory for the financially and physically capable Muslims to perform it at least once in the life. Hajj is considered among the big challenges facing Saudi Arabia and the Ministry of Health ${ }^{1}$. More than 2 million pilgrims perform rituals every year during the Hajj which is considered a peaceful mass gathering of pilgrims collecting in masses of nine people/ $\mathrm{m}^{2}$ from 200 countries at Mecca, Saudi Arabia. The Hajj comprises "effort-intensive prayers, supplications, and rituals for spiritual edification" ${ }^{2}$.

When rituals comes during the summer months, pilgrims are then exposed to harsh, hot, desert climate with outdoor temperatures which might exceeds $45^{\circ} \mathrm{C}$ and humidity might reach up to about $80 \%$. Hajj rituals at Mina, Arafat, and Muzdalifah include a minimally-clothed, moving grouping of about two million pilgrims exposed to physically challenging outdoor rituals and unsheltered night stays adding to waste of care fuel come out from vehicles for Hajaj transport, and the heat upright resulted from Hajaj gatherings (metabolic heat).

Temperatures at Makkah may increase to higher than $45^{\circ} \mathrm{C}$. Lack of acclimatization, intense physical exertion, reduced physical fitness, and exposed spaces produce heat sicknesses in many pilgrims. Heat illness, which is attributed to high temperatures in summer season, might be presented with mild symptoms like "heat cramps, edema, prickly heat and syncope or more severe conditions like heat exhaustion or heatstroke". Senility, chronic disease, overloading, physical exertion, lack of accommodation, and dehydration all are factors which determine the fate of heat illness ${ }^{4}$.

Body temperatures are moderated through intrinsic and extrinsic factors. Genetic factors, fitness, adaptation, diseases, drugs, and sleep pattern are considered intrinsic factors that alter individual risk for exertion heat stroke and outcomes. On the other hand, extrinsic factors included; exercise amount and duration, dressing and equipment, high ambient temperature, high relative moisture, and solar energy, 5 .

Heat exhaustion, one of heat illnesses where body temperature is elevated but still $<40^{\circ} \mathrm{C}$, occurs when persons are exposed to vigorous physical exertion and environmental heat stress. In such condition, the central nervous system function is normal ${ }^{7}$.

Heat stroke, which occurs when body temperature go above $41^{\circ} \mathrm{C}$, is considered to be the most severe form of the heat-induced disorders. In such condition, neurological disorders like an hydrosis might occur in some cases. Typical heat stroke occurs in persons like infants, elderly have weak warmth-defense mechanisms although exertional heat stroke happens 
in healthy, young adults during high-performance activities in hot environment ${ }^{8}$.

This work aimed to review the prevalence of heat illness in general and heat stroke in specific among the pilgrimage during Hajj and summarize the reasons that make pilgrimage more liable to develop heat stroke. The review also describes, in brief, the process of acclimatization to heat stress and the impact of heat stress on the body besides summarizing the common clinical presentation of heat stroke.

\section{PREVALENCE OF HEAT STROKE AMONG PILGRIMAGE}

Heatstroke was reported as a main cause of fear worldwide during the second half of the $20^{\text {th }}$ century due to rapid urbanization, industrial development, and subsequent climate alteration. ${ }^{2}$. Studies on mass gatherings and environmental threats revealed that an increase in temperature by one degree, from $20^{\circ} \mathrm{C}$ to $21^{\circ} \mathrm{C}$, lead to an elevation in the number of persons need medical care by more than $11 \%$. Furthermore, temperatures more than $27^{\circ} \mathrm{C}$ caused rise in the incidence of patient illness ${ }^{9}$.

During the Hajj, historical high morbidity and mortality rates were recorded due to heat illnesses ${ }^{2}$. Different characteristics of heat illness occurred in Saudi Arabia, regarding epidemiological and environmental circumstances have been frequently studied ${ }^{10}$. During the Hajj in 2016, 80 patients (29\%) out of 267 patients at four hospitals in the Mina and Arafat regions were suffering from heatstroke and resulted in a mortality rate of $6.3 \%$ and with the mean age of $54.0 \pm 16$ years. It was concluded that senility and diabetes mellitus are common risk factors for heat illness among pilgrims ${ }^{4}$. Kenney WL $2003^{12}$ reported that old age subjects are liable to heat illness as the blood supply to the skin, function of the sweat glands, cardiac function, renal function and thirst sensation all are reduced.

Noweir $\mathrm{MH} 2008^{13}$ reported that the highest rate of heat mortalities happened during $1409 \mathrm{H}$ and 1412 Hajj as the recorded maximum temperatures reached $48.7^{\circ} \mathrm{C}$ and $47.6^{\circ} \mathrm{C}$ respectively. Holy Makkah area had the highest recoded incidence of these mortalities, since pilgrims spend much long times in Makkah compared with Arafat and Mina.

\section{WHY PILGRIMAGES ARE LIABLE TO DEVELOP HEAT STROKE?}

Actually, most pilgrims don't tolerate heat exposure due to weakness which lead to many heat illnesses and finally heat stroke. Furthermore, some conditions e.g. the topographic environment of some Hajj areas as well as the conduct of various groups of the pilgrims might increase the heat exposure and the resulted heat stress. The topographic nature includes the open spaces exposed to sun rays engaged with Hajaj in Arafat and Mina and the presence of many high constructions, which obstruct normal air and cooling in some areas of Ghazzah and Aziziah. The behavior of the Hajeej that synergizes heat exposure like inadequate aeration in various tents present in Arafat and Mina, living and sleeping of some deprived pilgrims in sunny roads and areas, ignorant pilgrims about the impact of heat exposure and ways to protect themselves and finally the incorrect believes of some pilgrims about Hajj rituals, such as "living in open areas and not in tents, and using buses without roofs for transport, while women dress in black clothing that completely absorb sun radiated heat"13.

All the aforementioned factors are participating in the problem of heat stress among pilgrims, leading to some troubles such as; incapability to perform the jobs of Hajj due to heat exhaustion principally among pilgrims of somewhat "cold countries" who are not adapted to the tropical and subtropical climates, adding to the senile pilgrims. Other might suffer from having skin eruption and heat cramp or heat stroke resulting in certain cases, to death. Heat exhaustion defined as "a mild form of heat illness, may be one of a series of events leading to heat stroke". Early discovery of heat exhaustion in Hajaj is important to minimize or avoid the manifestation of fatal heat stroke ${ }^{14-18}$

Risk factors for heat stroke include the circumstances which affect thermo regulation and inhibit removal from a hot environment, or hinder hydration or cooling such as old or young ages, cardiovascular disease including hypertension, diabetes mellitus, CNS disorders, liver and kidney disorders or physical disability ${ }^{7}$.

\section{ACCLIMATIZATION TO HEAT STRESS AND ROLE OF STRESS PROTEINS}

The ability of the body to enhance the response and adaptation to heat stress over time is named acclimatization. It is a crucial component that controls how well an athlete tolerates extreme heat. It takes at least 10 to 14 days of sever exercise in order to increases body temperature to at least $38.5 \mathrm{C}$ for at least one hour for full acclimatization to occur ${ }^{7}$.

If heat stress occurs, this stage of acute phase response started and cellular protection is facilitated by the formation of the heat shock proteins (HSPs) ${ }^{19-}$ ${ }^{21}$. Heat shock proteins are "a family of proteins that are formed by cells when are exposed to stressful conditions". They were first defined in association with heat shock, but are currently known to be produced during exposure to other stresses like "cold UV light and during wound healing or tissue remodeling"22-24.

HSPs regulate the tissue reaction to different stressors through numerous ways of cellular activity. They prevent disaggregation of denatured proteins 
and help in the re-folding of denatured proteins into their normal assembly. HSPs also reduce the damage of epithelial barrier, prevent endotoxin leak through the intestine wall, and reduce arterial hypotension in order to lessen cerebral ischemia and neural damage, interfere with oxidative stress and stop the apoptotic cell paths in order to permit cell survival ${ }^{25-28}$.

During heat acclimation the levels of HSP70 are elevated and its half-life becomes longer and this is considered a biochemical protective mechanism ${ }^{29}$. On the other hand, Wang ZZ et al ${ }^{30}$ observed that HSP70 levels were reduced in some of patients suffering from heat stroke which is more observable in severe heat stroke. Li PL $2001^{31}$ reported that anti-HSP70 antibodies administration into the hypothalamus induced heat stroke. On the other hand, elevated HSP70 antibody might lead to the reduced levels of HSP70, with subsequent acceleration of the occurrence of heat stroke. During the uncompensated stage, heat stroke progress to a multi organ failure and hyperthermia ${ }^{32,33}$.

FIGURE I: Stress response mediated by Heat shock protein (Hsp) which preventing protein degradation and assisting with maintaining cellular homeostasis. (Adapted from Wang W 2004) ${ }^{27}$

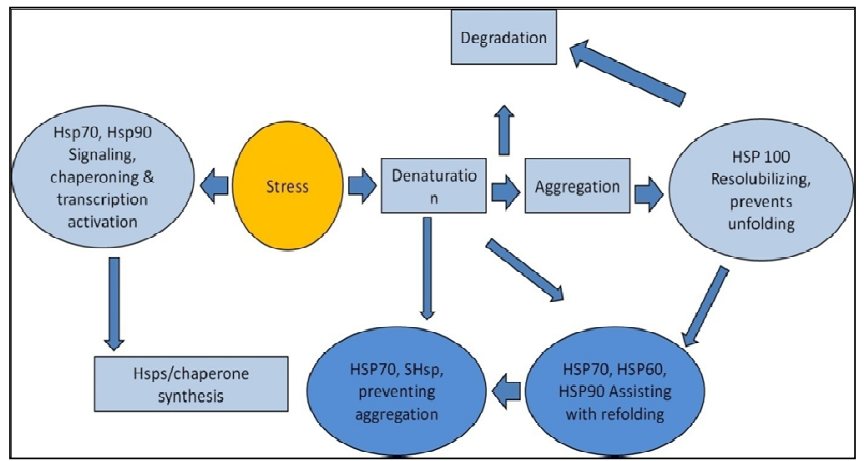

THE EFFECTS OF HEAT ELEVATION ON THE DIFFERENT BODY SYSTEMS:

Body temperature is generated as a result of cellular metabolism adding to temperature gained from the surrounding environment. Accumulated heat burden necessity be lost at the same speed as it is was acquired in order to keep body temperature within the normal level. During the compensatory phase, a rise in body temperature stimulates peripheral and central heat receptors, increases the cardiac output and induces vasodilation in cutaneous blood vessels, as well as enhances sweat secretion ${ }^{34,35}$. The active sympathetic-mediated cutaneous vasodilatation occurs in case of increased body temperature is accompanied by splanchnic vasoconstriction which decreases perfusion to the viscera, predominantly to the intestine and the kidney ${ }^{36,37}$. When this regulatory mechanism failed to reduce the body temperature, sweating started and the full sweat rates occurred when the body temperature raised up to $39 \mathrm{C}^{34}$. Electrolyte imbalance can result due to sweating and lead to the heat cramps during which the person is suffering from short-lived, painful contractions of skeletal muscles throughout or next working day in the heat for long time ${ }^{38}$.

This sweat induced fluid losses, leads to hypohydration, decreased cardiac output and escape of body fluid to the interstitial fluid space with subsequent cardiovascular collapse. If heat stress goes beyond this compensated stage, the central venous pressure declines markedly leading to more rise in body core temperature with subsequent failure in the thermoregulatory mechanism and the progress to heat stroke ${ }^{39}$.

Ischemia and hyperpermeability of the gut due to splanchnic vasoconstriction occurs also with hyperthermia and leads to reduced hepatic lactic acid removal and acidosis ${ }^{40}$. This lactic acidosis enhances the ATP-dependent Na1-K1 pump with subsequent production of more heat, reduced mitochondrial function and cellular energy production ${ }^{28}$. Severe hyperthermia also leads to increased intracellular $\mathrm{Ca}+{ }^{41}$.

Damaged cell membranes and intracellular channels leads to shock induced by endotoxin entered to the circulation with subsequent hypotension, tachycardia, and reduced blood flow to the different organs ${ }^{42}$. Endotoxemia also resulted in enhanced formation and secretion of inflammatory cytokines and the endothelial vasoactive factors like nitric oxide. All these factors together with disturbed intracellular ion balance lead to a 'vicious cycle' that is considered a hallmark of heat stroke and circulatory collapse and is associated with increased intracranial pressure, reduced cerebral blood supply, as well as marked neuronal affection ${ }^{28,43}$. Heat stress also resulted in augmented cellular metabolic changes as well as diminished splanchnic blood supply, intestinal and liver cell hypoxia and production of highly reactive oxygen and nitrogen species ${ }^{44}$.

\section{CLINICAL PRESENTATION OF HEAT STROKE}

The attack of heat stroke may occur suddenly or may be proceed by prodromal symptoms such as headache, dizziness, confusion. In the acute stage, it may be presented by anxiety, dizziness, fainting, and headache and might progress to stupor, semicoma or coma and convulsion due to reduced cerebral blood flow and elevated intracranial pressure. The patients usually manifest delirium, convulsions, and coma. These manifestations starts early due to the sensitivity of the central nervous system to heat stress ${ }^{43}$.

Since skin has ceased, the patient is flushed and dry, even in the axilla and groin, and hot and body 
temperature usually more than 40c. Proteinuria, hematuria and raised blood urea level are common associated changes. Acute tubular necrosis with oliguric renal failure occurs in about $10 \%$ of cases. Hepatic damage may cause jaundice and about $10 \%$ of cases presented with hepatic necrosis which may be sever and cause death. Hypotension and circulatory collapse may be presented ${ }^{45}$.

Coagulation disturbance as purpura and bleeding is considered a common presentation. GIT disorder as diarrhea and vomiting may be associated with blood when hemorrhage occurs with massive hematemesis and melena and electrolytes disturbance as hypokalemia and acidosis raised. Elevated serum enzymes have diagnostic and prognostic value ${ }^{44}$.

Memish L $2012^{3}$ reported that, most of the electrocardiographic changes noticed in patient with heat stroke were non-specific to such condition. He reported that "the mean heart rate was significantly higher $(120 \pm 24)$ per minute due to the higher core temperature in the heat stroke and heat exhaustion patients". The relative bradycardia in some patients might be attributed to an increase in the intracranial pressure. In only five out of 34 patients, electrocardiographic were totally normal while sinus tachycardia was noticed in twenty seven out of 34 patients and ischemic ECGs changes noticed in nine out of 34 patients.

Actually, during Hajj, extra physical activities are performed and subsequently oxygen demand is augmented. The increase in minute volume supplies this oxygen at the beginning, therefore hyperventilation is considered as one of the "respiratory clinical manifestations" in heat-induced illness. In addition, anxiety is commonly observed during heat stress nevertheless its contribution to hyperventilation is not clear. Later on, the patient develops shallow and rapid respiration during heat illness. On the other hand, hypoxia is not recorded or observed before the use of pulse oximetry. If hypoxia occurs, its severity will be depends on age and the comorbidities. Investigation of blood gases during heat stroke revealed great alternation in acid-base status in addition to increased level of serum creatinine and electrolyte disturbances ${ }^{4,46}$.

During Hajj, pilgrims are guided to stay in shelters to be protected from the direct sun rays, use sun block and take ample fluids ${ }^{47}$. Pilgrims suffering from heat illness and heat stroke are treated based on heat illness guidelines including rapid reduction of the body temperature using the conventional methods, oral or intravenous fluid therapy, $\mathrm{O} 2$ administration by face mask and sedation to control agitation and confusion. Blood tests to exclude organ damage, according to patient conditions ${ }^{48}$.
It is worth to mention that the ministry of health at Saudi Arabia could effectively alleviate and manage the impact of high heat events on pilgrims and reduce the huge preventable expenditure resulted from the heat related illnesses after introducing the National Hajj Extreme Heat Strategic plan. This honorable responsibility requires the ministry of health to devote all of its resources and efforts to provide a healthy pilgrims and visitors to the holy places. Among the responsibilities of the Heat Illnesses Command and Control Center (HICCC) is to conduct researches designed to study new measures for prevention and management of heat related illnesses annually ${ }^{49}$.

In summary, prevention and management of threats and protecting the health and lives of pilgrims requires effective cooperation between numerous agencies within and outside the Saudi Arabia ${ }^{50}$. This review described the prevalence the causes of heat illness among the pilgrimage during Hajj and explore, in brief, the process of acclimatization to heat stress and the impact of heat stress on the body. It could be concluded that increased patient education and awareness about heat illnesses and its risk factors and preventive measures against it might decrease the incidence and complications of such condition. The Hajj can therefore provide important lessons for setting up and maintaining inter-sectoral collaborations. It also gives a good chance for conducting researches in all aspects of mass gatherings as well as in health promotion and electronic disease surveillance capacity building.

\section{REFERENCES}

1. Memish ZA, McNabb SJ, Mahoney F, Alrabiah F, Marano N, Ahmed QA, et al. Establishment of public health security in Saudi Arabia for the 2009 Hajj in response to pandemic influenza A H1N1. Lancet. 2009; 374(9703): 1786-91. doi: 10.1016/ S0140-6736(09)61927-9.

2. Khan ID, Hussaini SB, Khan S, Ahmad FMH, Faisal A, Salim MA, et al. Emergency Response of Indian Hajj Medical Mission to Heat Illness Among Indian Pilgrims in Tent-Clinics at Mina and Arafat During Hajj 2016. Int J Travel Med Glob Health. 2017 Dec;5(4):135-139. doi:10.15171/ ijtmgh.2017.26.

3. Memish L. Electrocardiographic Findings in Heat Stroke and exhaustion: A study on Makkah Pilgrims. J Saudi Heart Assoc. 2012; 24(1): 35-39. doi: 10.1016/j.jsha.2011.08.003.

4. Abdelmoety DA, El-Bakri NK, Almowalld WO, Turkistani ZA, Bugis $\mathrm{BH}$, Baseif $\mathrm{EA}$, et al. Characteristics of Heat Illness during Hajj: A Cross-Sectional Study. Biomed Res Int. 2018; 2018:5629474. doi: 10.1155/2018/5629474. 
5. Goodman EL, Knochel JP. Heat stroke and other forms of hyperthermia. In: Mackowiak PA, ed. Fever: Basic Mechanisms and Management. New York: Raven Press; 1991:267-287.

6. Epstein Y. Exertional Heat stroke: Lessons we tend to forget. Am J Med Sports. 2000: 2: 143-52.

7. Alghamdi SA, Al-Salloom Al. Heat Illnesses In: A Pocket Guide for Clinicians during Haij 1437. $7^{\text {th }}$ ed. Ministry of Health, King Fahd National Library Cataloging in Publication Data; 2016.

8. Leon LR, Kenefick RW. In: Auerbach PS, editor. Wilderness medicine, 6th ed. Philadelphia, PA: Elsevier, 2012:215-31.

9. Soomaroo L, Murray V. Weather and environmental hazards at mass gatherings. PLoS Curr. 2012; 4: e4fca9ee30afc4. doi:10.1371/4fca9ee30afc4.

10. Dzaraly N.D., Rahman NI, Rahman A, Simbak NB. Patterns of communicable and non-communicable diseases in pilgrims during Hajj. Res J Pharm Tech. 2011; 7(9): 1052-59.

11. Sindy Al, Baljoon MJ, Zubairi NA, Dhafar KO, Gazzaz ZJ, Deiab BA, et al. Pattern of patients and diseases during mass transit: The day of Arafat experience. Pak J Med Sci. 2015; 31(5): 1099-1103. doi: 10.12669/pjms.315.8017

12. Kenney WL, Munce TA. Invited review: Aging and human temperature regulation. J Appl Physiol (1985). 2003; 95(6): 2598-603.

13. Noweir MH, Bafail AO, Jomoah IM. Study of heat exposure during Hajj (pilgrimage). Environ Monit Assess. 2008; 147(1-3): 279-95. doi:10.1007/ s10661-007-0120-6.

14. American Industrial Hygiene Association (AlHA). The stress of hot environment. American Industrial Hygiene Association, Fairfax, VA, USA. 1973.

15. National Institute for Occupational Safety and Health (NIOSH). Occupational exposure to heat and hot environments: Revised criteria. National Institute for Occupational Safety and Health, DHHS (NIOSH), Cincinnati, OH, USA: 2016. Publication No. 2016-106.

16. Mutchler JE. Heat stress: Its effect, measurement and control. In: GD Clayton \& FE Clayton, Eds. Patty's industrial hygiene and toxicology, 4th ed. New York, USA: Wiley. 1991; Vol. I-A. pp. 763838.

17. Al-Ghamdi MA. Assessment and improvement of thermal conditions inside pilgrimage tents and in Makkah in Saudi Arabia. Ph.D. Thesis, School of Architecture, University of New Castle-UponTnye, NE1-7RU, UK. 1993.

18. Ramsey JD, Bashir MY. Thermal standards and measurements techniques. In: DiNardi S, Editor. The occupational environment: Its evaluation, control and management. American Industrial Hygiene Association. Fairfax, VA, USA: 1997; p. 660-691.

19. Lin MT. Pathogenesis of an experimental heatstroke model. Clin Exp Parmacol Physiol. 1999: 26(10): 826-27.

20. Leon LR. Heat stroke and cytokines. Prog Brain Res. 2007; 162: 481-524.

21. Sonna LA, Sawka MN, Lilly CM. Exertional heat illness and human gene expression. Prog Brain Res. 2007; 162: 321-46.

22. Matz JM, Blake MJ, Tatelman HM, Lavoi KP, Holbrook NJ. Characterization and regulation of cold-induced heat shock protein expression in mouse brown adipose tissue.AM J Physiol.1995; 269(1 Pt 2): R38-47. doi:10.1152/ajpregu. 1995.269.1.R38.7631901.

23. Cao Y, Ohwatari N, Matsumoto T, Kosaka M, Ohtsuru A, Yamashita S. TGF-beta1 mediates 70$\mathrm{kDa}$ heat shock protein induction due to ultraviolet irradiation in human skin fibroblasts. Pflügers Archiv. 1999; 438(3): 239-44. doi:10.1007/s00424 0050905.

24. Laplante AF, Moulin V, Auger FA, Landry J, Li H, Morrow $G$, et al. Expression of heat shock proteins in mouse skin during wound healing. J Histochem Cytochem. 46(11): 1291-301. doi: $10.1177 / 002215549804601109$.

25. Yang YL, Lin MT. Heat shock protein expression protects against cerebral ischemia and monamine overload in rat heatstroke. Am J Physiol. 1999; 276(6): H1961-7. doi: 10.1152/ajpheart.1999. 276.6.H1961.

26. Lin MT, Chang CP. The neuropharmacological basis of heat intolerance and its treatment. J Thermal Biol. 2004; 29: 463-69. doi:10.1016/j. jtherbio.2004.08.015.

27. Wang W, Vinocur B, Shoseyov O, Altman A. Role of plant heat-shock proteins and molecular chaperones in the abiotic stress response. Trends Plant Sci. 2004; 9(5): 244-52.

28. Yan YE, Zhao YQ, Wang $H$, Fan $M$. Pathophysiological factors underlying heatstroke. Med Hypotheses. 2006; 67(3): 609-17.

29. Yamada PM, Amorim FT, Moseley P, Robergs R, Schneider SM. Effect of heat acclimation on heat shock protein 72 and interleukin-10 in humans. J Appl Physiol(1985). 2007: 103(4): 1196-204.

30. Wang ZZ, Wang CL, Wu TC, Pan HN, Wang SK, Jiang JD. Autoantibody response to heat shock protein 70 in patients with heatstroke. Am J Med. 2001; 111(8): 654-57.

31. Li PL, Chao YM, Chan SH, Chan JY. Potentiation of baroreceptor reflex response by heat shock protein 70 in nucleus tractus solitarii confers 
cardiovascular protection during heatstroke. Circulation. 2001; 103(16): 2114-9.

32. Horowitz M. Heat acclimation and cross tolerance against novel stressors: genomic- physiological linkage. Prog Brain Res. 2007; 162: 373-92.

33. Leon LR, Helwig BG. Heat stroke: role of the systemic inflammatory response. J Appl Physiol (1985). 2010; 109: 1980-8. doi: 10.1152/ japplphysiol.00301.2010.

34. Roberts MF, Wenger CB, Stolwijk JA, Nadel ER. Skin blood flow and sweating changes following exercise training and heat acclimation. J Appl Physiol Respir Environ Exerc Physiol. 1977; 43 (1): 133-7.

35. Rowell LB. Cardiovascular aspects of human thermoregulation. Circ Res. 1983; 52(4): 367-79

36. Johnson JM, Proppe DW. Cardiovascular adjustments to heat stress. In: Blatteis CM, Fregly M, editors. Handbook of physiology: Adaptations to the Environment. American Physiological Society; Bethesda, MD: 1996. pp. 215-243.

37. Charkoudian N. Skin blood flow in adult human thermoregulation: how it works, when it does not, and why. Mayo Clin Proc. 2003; 78(5): 603-12.

38. Gaffin SL, Hubbard RW. Pathophysiology of heatstroke, In: Pandolf KB, Burr RE, editors. Medical Aspects of Harsh Environments. US Defense Dept. Army Office of the Surgeon General, 2001:161-208. Available from: http:// www.bordeninstitute.army. $\mathrm{mil} / \mathrm{medaspofhars}$ henvrmnts/.

39. Hales JRS. Proposed mechanisms underlying heat stroke. Heat stress: physical exertion and environment. Transactions of the Menzies Foundation. 1987; 14: 47-56.

40. Hall DM, Buettner GR, Oberley LW, Xu L, Matthes $R D$, Gisolfi CV. Mechanisms of circulatory and intestinal barrier dysfunction during whole body hyperthermia. Am J Physiol Heart Circ Physiol.
2001: 280(2): H509-21

41. Gaffin SL, Hubbard RW. Pathophysiology of heatstroke. Medical Aspects of Harsh Environments. 2001; 1: 161-208.

42. Lambert GP. Role of gastrointestinal permeability in exertional heatstroke. Exerc Sport Sci Rev. 2004: 32(4): 185-90.

43. Bouchama A, Knochel JP. Heat stroke. New Engl J Med. 2002; 346(25): 1978-88.

44. Chang CK, Chang CP, Liu SY, Lin MT. Oxidative stress and ischemic injuries in heat stroke. Prog Brain Res. 2007; 162: 525-46.

45. Atha WF. Heat-related illness. Emerg Med Clin North Am. 2013; 31(4): 1097-108. doi: 10.1016/j. emc.2013.07.012.

46. Yaqub B, Al Deeb S. Heat strokes: aetiopathogenesis, neurological characteristics, treatment and outcome. J Neurol Sci. 1998; 156(2): 144-51.

47. AL Masud SM, Abu Bakar A, Yussof S. Determining the types of diseases and emergency issues in Pilgrims during Hajj: A literature review. Int J Adv Comp Sci Appl. 2016; 7(10): 86-94. doi:10.14569/IJACSA.2016.071011

48. Shujaa A, Alhamid S. Health response to Hajj mass gathering from emergency perspective, narrative review. Turk J Emerg Med. 2015; 15(4): 172-6. doi:10.1016/j.tjem. 2015.02.001

49. Ministry of Health KSA. National Hajj Extreme Heat Strategy. Technical Supervisory Committee during Hajj. Kingdom Of Saudi Arabia. 2016. Available from: https://www.moh.gov.sa/en/Hajj/ PublicationsAwareness/Publications/Documents/ National-Hajj-Extreme-Heat-Strategic-Strategy. pdf.

50. Memish ZA, Zumla A, McCloskey B, Heymann D, Al Rabeeah AA, Barbeschi $M$, et al. Mass gatherings medicine: international cooperation and progress. Lancet. 2014; 383(9934): 2030-2. doi: 10.1016/S0140-6736(14)60225-7.

AUTHOR AFFILIATION:

\section{Suhaila Qari}

Department of Biological Sciences, Faculty of Science

King Abdulaziz University

Jeddah, Saudi Arabia.

Email: sqari@kau.edu.sa 